\title{
Prognostic significance of preoperative plasma D-dimer level in patients with surgically resected clinical stage I non-small cell lung cancer: a retrospective cohort study
}

\author{
Kaoru Kaseda ${ }^{1 *}$, Keisuke Asakura$^{1}$, Akio Kazama ${ }^{2}$ and Yukihiko Ozawa ${ }^{3}$
}

\begin{abstract}
Background: Plasma D-dimer level, a marker of hypercoagulation, has been reported to be associated with survival in several types of cancers. The present study aimed to evaluate the prognostic significance of preoperative Ddimer levels in patients with surgically resected clinical stage I non-small cell lung cancer (NSCLC).

Methods: Participants comprised 237 patients with surgically resected clinical stage I NSCLC. In addition to factors such as age, sex, and smoking status, the association between preoperative D-dimer level and survival was explored.

Results: Patients were divided into two groups according to D-dimer level: Group A, $\leq 1.0 \mu \mathrm{g} / \mathrm{ml}(n=170)$; and Group $B_{1}>1.0 \mu \mathrm{g} / \mathrm{ml}(n=67)$. The 5-year recurrence-free survival rate was 81.6\% for Group A and 66.6\% for Group B ( $p<0$. 001). The 5-year overall survival rate was $93.6 \%$ for Group A and 84.7\% for Group B ( $p=0.002)$. Multivariate survival analysis identified D-dimer level as an independent prognostic factor, along with age, maximum standardized uptake value of the primary tumor, and pathological stage.
\end{abstract}

Conclusions: Preoperative D-dimer level is an independent prognostic factor in patients with surgically resected clinical stage I NSCLC.

Keywords: D-dimer, Non-small cell lung cancer, Prognosis

\section{Background}

Patients with malignant tumors sometimes develop hypercoagulability, which can present as conditions like disseminated intravascular coagulation (DIC) and venous thromboembolism (VTE). Systemic hypercoagulability is frequently observed in patients with advanced-stage cancer, even if no thrombosis is present. One previous study expanded the definition of Trousseau's syndrome to include chronic disseminated intravascular coagulopathy associated with microangiopathy, verrucous endocarditis and arterial emboli in patients with cancer, and this syndrome is frequent among patients with mucin-

\footnotetext{
*Correspondence: kaseda@wb4.so-net.ne.jp

'Department of Thoracic Surgery, Sagamihara Kyodo Hospital, 2-8-18

Hashimoto, Midori-ku, Sagamihara, Kanagawa 252-5188, Japan

Full list of author information is available at the end of the article
}

positive carcinoma [1]. More recently, the term has been applied to a wide variety of clinical situations, from classic descriptions to any form of coagulopathy occurring against a background of malignancy [2].

Physiological degradation of fibrin results in plasma D-dimer (D-dimer), and levels of this stable end product are increased by significant fibrin formation and fibrinolysis. D-dimer level thus offers an indicator of the hypercoagulable state often evident in patients with thrombosis or DIC. As levels of D-dimer are increased following clotting, measurement of D-dimer concentration is a standard initial assessment for suspected cases of acute VTE [3]. Increased concentrations of D-dimer are also seen with other situations, including infection, pregnancy, and cancer, and after trauma or surgery. 
Tumor-induced coagulation and fibrin formation have been reported as prerequisite to tumor angiogenesis, metastasis and invasion, with cross-linked fibrin in the extracellular matrix providing the basis for endothelial cell and tumor cell migration during angiogenesis and invasion $[4,5]$. Various investigations have reported that D-dimer levels, reflecting the degree of coagulation and fibrinolytic activation, correlate with tumor stage, response to chemotherapy and prognosis for several types of cancer [6-9], including non-small cell lung cancer (NSCLC) [9-11]. However, the relevance of D-dimer level for primary lung cancer has yet to be established. This study aimed to elucidate the prognostic significance of preoperative D-dimer levels after complete resection of clinical stage I NSCLC.

\section{Methods}

\section{Patient eligibility}

Between April 2007 and August 2013, a total of 306 consecutive patients with potentially resectable NSCLC underwent measurement of D-dimer levels at Sagamihara Kyodo Hospital, Kanagawa, Japan. D-dimer level was measured within 4 weeks of surgery. We reviewed the data from 237 of these patients who were diagnosed with clinical stage I NSCLC according to the seventh edition of the TNM Staging Classification for Lung Cancer [12]. Patients who underwent incomplete resection or neoadjuvant chemotherapy/radiotherapy were excluded.

In addition to the D-dimer level, we reviewed the medical records of each patient for the following clinicopathological information: age, sex, smoking habit, serum concentration of carcinoembryonic antigen (CEA), extent of pulmonary resection, tumor location, maximum standardized uptake value (SUVmax) of the primary tumor, maximum tumor diameter, histological type, grade, pleural invasion, and pathological stage. All clinical, intraoperative, radiological, and pathological findings from two hospitals in Kanagawa, Japan (Sagamihara Kyodo Hospital and Yuai Clinic) were reviewed. Histological classification of NSCLC was based on the criteria of the World Health Organization [13]. Pre- and postoperative staging was based on the TNM staging system. Data collection and analyses were approved, and the need to obtain written informed consent from each patient was waived by the first author's institutional review board, due to the retrospective nature of this investigation.

\section{Computed tomography}

Diagnostic-quality contrast-enhanced computed tomography $(\mathrm{CT})$ of the chest with a slice thickness of $5 \mathrm{~mm}$ was performed for all patients. A tumor was deemed central if the center was located in the inner one-third of the lung parenchyma (adjacent to the mediastinum) on transverse CT. Peripherally located tumors were identified as those centered in the outer two-thirds of the lung parenchyma on transverse CT. The maximal diameter of lung nodules was measured on contrastenhanced chest CT. All imaging was performed within 4 weeks of surgery.

\section{Integrated ${ }^{18} \mathrm{~F}$-fluorodeoxyglucose positron emission tomography imaging}

Each patient underwent integrated ${ }^{18} \mathrm{~F}$-fluorodeoxyglucose positron emission tomography/CT (FDG-PET/CT) imaging before surgical resection. All integrated FDGPET/CT imaging was performed within 4 weeks of surgery. After fasting for $6 \mathrm{~h}$, FDG $(3.5 \mathrm{MBq} / \mathrm{kg}$ body weight) was intravenously injected if the blood sugar level was lower than $200 \mathrm{mg} / \mathrm{dl}$. Image acquisition was started $60 \mathrm{~min}$ after the injection using a single PET/CT combined scanner (Eminence-SOPHIA; Shimadzu, Kyoto, Japan) [14]. Image emission data from the eyes to the mid-thigh area were continuously acquired over a period of approximately $20 \mathrm{~min}$. After attenuation corrections were made for the resulting image data, reconstruction was performed using a dynamic row-action expectation maximization algorithm [15]. The reconstructed sectional images were then evaluated both visually and quantitatively using the $S U V_{\text {max }}$ inside a volume of interest (VOI) placed on the lesions. $\mathrm{SUV}_{\max }$ was calculated as follows: [(maximum activity in VOI) / (volume of VOI)] / [(injected FDG dose)/(patient weight)]. The quality of radiation measurements of the PET/CT scanner was assured by calibration in accordance with $\mathrm{Na}$ tional Electrical Manufacturers Association NU-2 2001 standards [16].

Nodal uptake with an $\mathrm{SUV}_{\max }>2.5$ was considered positive. To determine the SUV, a cylindrical region of interest (ROI) was placed over the tumor site manually on the hottest trans-axial slice. Activity within the ROI was determined and expressed as the SUV, defined as the ratio of activity in the tissue to the decay-corrected activity injected into the patient. All SUV measurements were normalized for patient body weight. $\mathrm{SUV}_{\max }$ within an ROI was used as the reference measurement.

Three experienced radiologists individually analyzed the integrated FDG-PET/CT images, with the final assessment made by consensus if initial assessments differed.

\section{Surgical resection}

All patients underwent anatomical lung resection (lobectomy or greater and segmentectomy) and radical lymphadenectomy in our hospital. All surgical resections were performed by thoracic surgeons at Sagamihara Kyodo Hospital. All surgical resection techniques were standardized. Systematic lymph node dissection was performed in all patients according to the criteria of the 
American Thoracic Society, removing at least three hilar and three mediastinal stations.

\section{Pathological examination}

All resected tumor specimens were examined by experienced pulmonary pathologists. Histological classification of NSCLC was based on WHO classifications. Dissected lymph nodes were histologically examined following hematoxylin and eosin staining.

\section{Statistical analysis}

Statistical analysis was performed using SPSS version 23.0 software (IBM Corporation, Armonk, NY). Survival curves were constructed using the Kaplan-Meier method. Recurrence-free survival (RFS) probabilities and overall survival (OS) rates were compared using the logrank test. The Cox proportional hazard model was used to estimate hazard ratio (HR) with $95 \%$ confidence interval (CI) for uni- and multivariate analyses. All tests were two-sided, and values of $P<0.05$ were considered statistically significant. Factors identified as significant in univariate analysis $(P<0.05)$ were entered into the multivariate analysis.

\section{Results}

\section{Patient characteristics}

Patients were divided into two groups according to the D-dimer level: Group A, $\leq 1.0 \mu \mathrm{g} / \mathrm{ml}(n=170)$; and Group B, $>1.0 \mu \mathrm{g} / \mathrm{ml}(n=67)$. Patient characteristics are shown in Table 1. Participants comprised 140 men and 97 women, ranging in age from 31 to 85 years (median, 69 years). Median observation period in the survivors was 60.0 months (range, 2-110 months). Associations between $\mathrm{D}$-dimer level and clinicopathological characteristics are shown in Table 2. D-dimer level correlated with serum CEA $(p<0.001)$, SUVmax of the primary tumor $(p<0.001)$, tumor size $(p=0.023)$, and pathological stage $(p=0.003)$.

\section{Survival analysis of patients with pathological stage I adenocarcinoma after surgical resection}

The 5-year RFS rate was $81.6 \%$ for Group A, and $66.6 \%$ for Group B ( $<0.001)$ (Fig. 1a). The 5-year OS rate was 93.6\% for Group A, and $84.7 \%$ for Group B $(p=0.002)$ (Fig. 1b).

Univariate survival analysis revealed age ( $<70$ vs. $\geq 70$, OS: HR 2.31 ; $95 \%$ CI $1.12-5.13)$, serum CEA $(\leq 5$ vs. $>5$, RFS: HR 2.11; 95\%CI 1.03-4.12, OS: HR 2.42; 95\%CI 1.31-5.46), SUVmax of the primary tumor ( $\leq 2.3$ vs. $>2.3$, RFS: HR 5.89; 95\%CI 3.45-14.2, OS: HR 3.89; 95\%CI 1.64-9.01), D-dimer level ( $\leq 1.0$ vs. $>1.0$, RFS: HR 2.62; 95\%CI 1.41-5.61, OS: HR 2.67; 95\%CI 1.23-5.12), pleural invasion (absent vs. present, OS: HR 2.42; 95\%CI 1.06-5.52) and
Table 1 Clinicopathological characteristics of 237 patients with clinical stage I NSCLC

\begin{tabular}{|c|c|}
\hline Variables & $\mathrm{n}(\%)$ or mean $\pm \mathrm{SD}$ \\
\hline Age at operation, y & $69.0 \pm 9.7$ \\
\hline \multicolumn{2}{|l|}{ Gender } \\
\hline Female & 97 (40.9\%) \\
\hline Male & 140 (59.1\%) \\
\hline \multicolumn{2}{|l|}{ Smoking habit } \\
\hline Never smoker & $94(39.7 \%)$ \\
\hline Ever smoker & $143(60.3 \%)$ \\
\hline \multicolumn{2}{|l|}{ Serum CEA, ng/ml } \\
\hline$\leq 5$ & $178(75.1 \%)$ \\
\hline$>5$ & $59(24.9 \%)$ \\
\hline \multicolumn{2}{|c|}{ Extent of pulmonary resection } \\
\hline Segmentectomy & $34(14.3 \%)$ \\
\hline Lobectomy or more & $203(85.7 \%)$ \\
\hline \multicolumn{2}{|l|}{ Tumor location } \\
\hline Central & $24(10.1 \%)$ \\
\hline Non-central & $213(89.9 \%)$ \\
\hline$S_{U} V_{\max }$ of primary tumor & $2.3 \pm 2.8$ \\
\hline \multicolumn{2}{|l|}{ D-dimer, $\mu \mathrm{g} / \mathrm{ml}$} \\
\hline$\leq 1.0$ & $170(71.7 \%)$ \\
\hline$>1.0$ & $67(28.3 \%)$ \\
\hline Tumor size, $\mathrm{cm}$ & $2.7 \pm 1.5$ \\
\hline \multicolumn{2}{|l|}{ Histological type } \\
\hline$A D$ & $188(79.3 \%)$ \\
\hline SQ & $36(15.3 \%)$ \\
\hline Others & $13(5.4 \%)$ \\
\hline \multicolumn{2}{|l|}{ Grade } \\
\hline 1 & $156(65.8 \%)$ \\
\hline $2 / 3 / 4$ & $81(34.2 \%)$ \\
\hline \multicolumn{2}{|l|}{ Pleural invasion } \\
\hline Absent & 209 (88.2\%) \\
\hline Present & $28(11.8 \%)$ \\
\hline \multicolumn{2}{|l|}{ Pathological stage } \\
\hline Stage I & $205(86.4 \%)$ \\
\hline Stage II & $19(8.2 \%)$ \\
\hline Stage III & $13(5.4 \%)$ \\
\hline
\end{tabular}

NSCLC non-small cell lung cancer, $S D$ standard deviation, CEA carcinoembryonic antigen, $A D$ adenocarcinoma, $S Q$ squamous cell carcinoma, $S U V_{\max }$ maximum standardized uptake value

pathological stage (Stage I vs. Stage II/III, RFS: HR 5.61; 95\%CI 3.22-9.12, OS: HR 3.91; 95\%CI $1.65-$ 8.98 ) as significant prognostic factors (Table 3). Multivariate survival analysis identified age ( $<70$ vs. 270, OS: HR 2.39; 95\%CI 1.09-5.24), SUVmax of the primary tumor $(\leq 2.3$ vs. $>2.3$, RFS: HR 3.78 ; $95 \% \mathrm{CI}$ 
Table 2 Association between D-dimer level and clinicopathological characteristics in patients with clinical stage I NSCLC

\begin{tabular}{|c|c|c|c|}
\hline \multirow[t]{3}{*}{ Variables } & GroupA:D-dimer, $\mu \mathrm{g} / \mathrm{ml} \leq 1.0$ & GroupB:D-dimer, $\mu \mathrm{g} / \mathrm{ml}>1.0$ & \multirow[t]{3}{*}{$P$ value } \\
\hline & $(n=170)$ & $(n=67)$ & \\
\hline & n (\%) & n (\%) & \\
\hline \multicolumn{4}{|l|}{ Age at operation, y } \\
\hline$<70$ & $82(48.1 \%)$ & $31(46.3 \%)$ & \multirow[t]{2}{*}{0.785} \\
\hline$\geq 70$ & $88(51.9 \%)$ & $36(53.7 \%)$ & \\
\hline \multicolumn{4}{|l|}{ Gender } \\
\hline Female & $68(40.0 \%)$ & $29(43.3 \%)$ & \multirow[t]{2}{*}{0.643} \\
\hline Male & $102(60.0 \%)$ & $38(56.7 \%)$ & \\
\hline \multicolumn{4}{|l|}{ Smoking habit } \\
\hline Never smoker & $70(41.2 \%)$ & $24(35.8 \%)$ & \multirow[t]{2}{*}{0.448} \\
\hline Ever smoker & $100(58.8 \%)$ & $43(64.2 \%)$ & \\
\hline \multicolumn{4}{|l|}{ Serum CEA, ng/ml } \\
\hline$\leq 5$ & $140(82.3 \%)$ & $38(56.7 \%)$ & \multirow[t]{2}{*}{$<0.001$} \\
\hline$>5$ & $30(17.7 \%)$ & $29(43.3 \%)$ & \\
\hline \multicolumn{4}{|c|}{ Extent of pulmonary resection } \\
\hline Segmentectomy & $24(14.1 \%)$ & $10(14.9 \%)$ & \multirow[t]{2}{*}{0.873} \\
\hline Lobectomy or more & $146(85.9 \%)$ & $57(85.1 \%)$ & \\
\hline \multicolumn{4}{|l|}{ Tumor location } \\
\hline Central & $16(9.4 \%)$ & $8(12.0 \%)$ & \multirow[t]{2}{*}{0.561} \\
\hline Non-central & $154(90.6 \%)$ & $59(88.0 \%)$ & \\
\hline \multicolumn{4}{|l|}{$S U V_{\max }$ of primary tumor } \\
\hline$\leq 2.3$ & $123(72.4 \%)$ & $28(41.8 \%)$ & \multirow[t]{2}{*}{$<0.001$} \\
\hline$>2.3$ & $47(27.6 \%)$ & $39(58.2 \%)$ & \\
\hline \multicolumn{4}{|l|}{ Tumor size, cm } \\
\hline$\leq 3$ & $118(69.4 \%)$ & $36(53.7 \%)$ & \multirow[t]{2}{*}{0.023} \\
\hline$>3$ & $52(30.6 \%)$ & 31 (46.3\%) & \\
\hline \multicolumn{4}{|l|}{ Histological type } \\
\hline$A D$ & 139 (81.7\%) & $49(73.1 \%)$ & \multirow[t]{2}{*}{0.140} \\
\hline Others & 31 (28.3\%) & 18 (26.9\%) & \\
\hline \multicolumn{4}{|l|}{ Grade } \\
\hline 1 & $113(72.4 \%)$ & $43(64.2 \%)$ & \multirow[t]{2}{*}{0.738} \\
\hline $2 / 3 / 4$ & $57(27.6 \%)$ & $24(35.8 \%)$ & \\
\hline \multicolumn{4}{|l|}{ Pleural invasion } \\
\hline Absent & $154(90.6 \%)$ & $55(82.0 \%)$ & \multirow[t]{2}{*}{0.068} \\
\hline Present & $16(9.4 \%)$ & $12(18.0 \%)$ & \\
\hline \multicolumn{4}{|l|}{ Pathological stage } \\
\hline Stage I & $154(90.6 \%)$ & $51(76.1 \%)$ & \multirow[t]{2}{*}{0.003} \\
\hline Stage II / III & 16 (9.4\%) & 16 (23.9\%) & \\
\hline
\end{tabular}

NSCLC non-small cell lung cancer, CEA carcinoembryonic antigen, AD adenocarcinoma, SUVmax maximum standardized uptake value

1.61-8.72, OS: HR 3.43; 95\%CI 1.36-8.61), D-dimer level ( $\leq 1.0$ vs. $>1.0$, RFS: HR 1.92; 95\%CI $1.33-2.91$, OS: HR 2.24; $95 \% \mathrm{CI} 1.05-4.69)$, and pathological stage (Stage I vs. Stage II/III, RFS: HR 4.01; 95\%CI 1.64-9.91, OS: HR 4.11; 95\%CI 1.65-9.98) as significant prognostic factors (Table 4).

\section{Discussion}

This retrospective investigation examined the prognostic significance of preoperative D-dimer concentrations in patients after surgical resection of clinical stage I NSCLC. Factors affecting the prognosis of surgically resected NSCLC have not yet been characterized in 


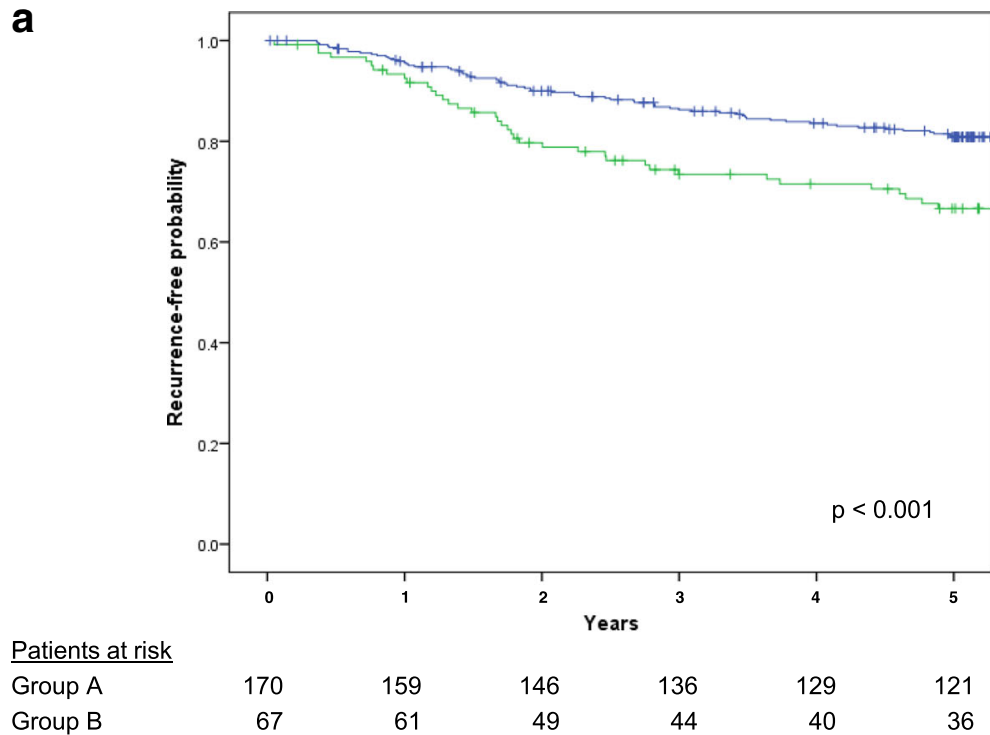

b

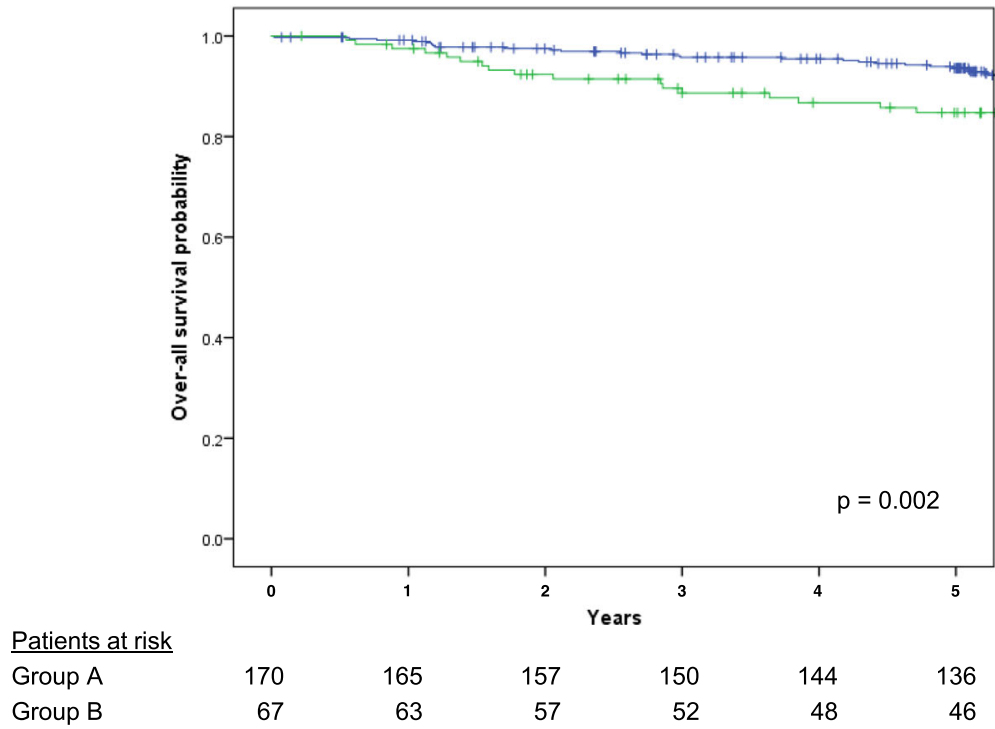

Fig. 1 a Recurrence-free survival of patients with surgically resected clinical stage I non-small cell lung cancer. The 5-year recurrence-free survival rate was $81.6 \%$ for Group A, and $66.6 \%$ for Group B $(p<0.001)$. b Overall survival of patients with surgically resected clinical stage I non-small cell lung cancer. The 5-year overall survival rate was $93.6 \%$ for Group A, and $84.7 \%$ for Group B ( $p=0.002)$

detail. However, clinicopathological factors such as positive cytological findings from pleural lavage, high preoperative concentrations of CEA, high tumor SUVmax and presence of lymphovascular invasion have been reported as associated with recurrence or decreased survival after surgery for NSCLC [17-19]. As a product of fibrin degradation, D-dimer is produced when crosslinked fibrin is broken down by plasmin-induced fibrinolysis. Concentrations of D-dimer are considered to represent a global biomarker of hemostasis and fibrinolysis. The processes of metastasis and tumor growth involve various interactions between the tumor and host.
Metastatic cancer cells must separate from the primary tumor, enter the circulation, attach to the vasculature of the destination, invade the tissue at this new site and establish neovasculature [20, 21]. Following initial cancer cell arrest in the vasculature of the destination organ, clotted plasma and platelets act in concert to stabilize circulating cancer cells by generating a thrombus that facilitates the attachment of cancer cells and allows invasion into the vessel wall [22]. Fibrin remodeling is involved in almost all the steps of metastasis, and plays a central role in neovascularization [20, 21]. Within the tumor extracellular matrix, cross-linked fibrin offers a 
Table 3 Univariate analyses for recurrence-free and overall survival in patients with clinical stage I NSCLC

\begin{tabular}{|c|c|c|c|c|}
\hline \multirow[b]{2}{*}{ Variables } & \multicolumn{2}{|l|}{ RFS } & \multicolumn{2}{|l|}{ OS } \\
\hline & HR $(95 \%$ Cl) & $P$ value & HR $(95 \%$ Cl) & $P$ value \\
\hline \multicolumn{5}{|c|}{ Age at operation, y } \\
\hline$<70$ & 1 & & 1 & \\
\hline$\geq 70$ & $1.12(0.56-2.14)$ & 0.762 & $2.31(1.12-5.13)$ & 0.031 \\
\hline \multicolumn{5}{|l|}{ Gender } \\
\hline Female & 1 & & 1 & \\
\hline Male & $1.13(0.54-2.28)$ & 0.668 & $1.02(0.78-1.52)$ & 0.869 \\
\hline \multicolumn{5}{|l|}{ Smoking habit } \\
\hline Never smoker & 1 & & 1 & \\
\hline Ever smoker & $1.22(0.88-1.72)$ & 0.281 & $1.21(0.86-1.82)$ & 0.225 \\
\hline \multicolumn{5}{|l|}{ Serum CEA, ng/ml } \\
\hline$\leq 5$ & 1 & & 1 & \\
\hline$>5$ & $2.11(1.03-4.12)$ & 0.049 & $2.42(1.31-5.46)$ & 0.019 \\
\hline
\end{tabular}

Extent of pulmonary resection

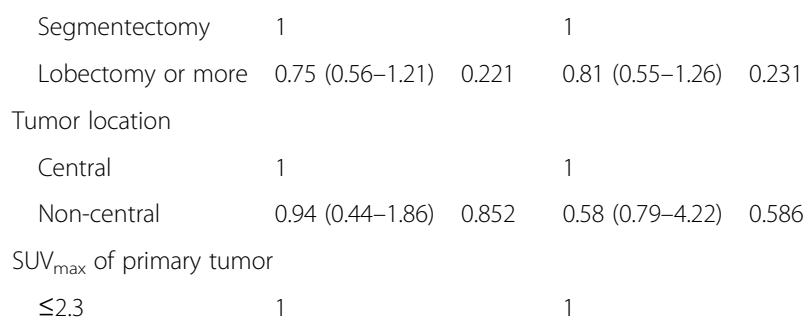

NSCLC non-small cell lung cancer, CEA carcinoembryonic antigen, $A D$ adenocarcinoma, SUVmax maximum standardized uptake value, RFS recurrence-free survival, $O S$ overall survival, $H R$ hazard ratio, $\mathrm{Cl}$ confidence interval
Table 4 Multivariate analyses for recurrence-free and overall survival in patients with clinical stage I NSCLC

\begin{tabular}{|c|c|c|c|c|}
\hline \multirow[b]{2}{*}{ Variables } & \multicolumn{2}{|l|}{ RFS } & \multicolumn{2}{|l|}{ OS } \\
\hline & HR $(95 \% \mathrm{Cl})$ & $P$ value & HR $(95 \% \mathrm{Cl})$ & $P$ value \\
\hline \multicolumn{5}{|c|}{ Age at operation, y } \\
\hline$<70$ & & & 1 & \\
\hline$\geq 70$ & - & - & $2.39(1.09-5.24)$ & 0.029 \\
\hline \multicolumn{5}{|c|}{ Serum CEA, ng/ml } \\
\hline$\leq 5$ & 1 & & 1 & \\
\hline$>5$ & $1.03(0.98-1.05)$ & 0.061 & $1.74(0.79-3.81)$ & 0.163 \\
\hline \multicolumn{5}{|c|}{ SUV $_{\max }$ of primary tumor } \\
\hline$\leq 2.3$ & 1 & & 1 & \\
\hline$>2.3$ & $3.78(1.61-8.72)$ & 0.002 & $3.43(1.36-8.61)$ & 0.008 \\
\hline \multicolumn{5}{|c|}{ D-dimer, $\mu \mathrm{g} / \mathrm{ml}$} \\
\hline$\leq 1.0$ & 1 & & 1 & \\
\hline$>1.0$ & $1.92(1.33-2.91)$ & 0.041 & $2.24(1.05-4.69)$ & 0.032 \\
\hline
\end{tabular}

Pleural invasion

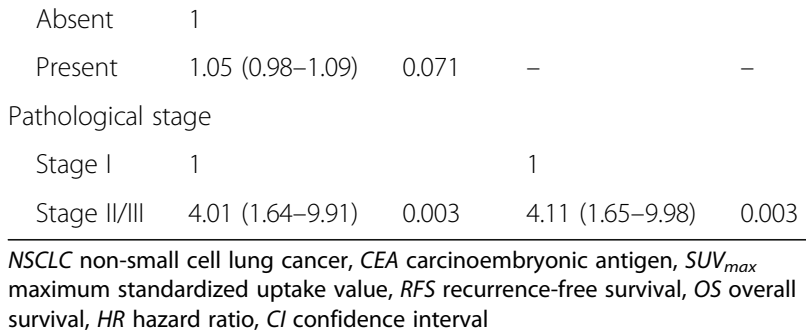

stable platform for endothelial cell migration during angiogenesis and for cancer cell migration during invasion. Even the early stages of tumor development show local fibrin deposition and initiation of angiogenesis [22]. Moreover, fibrin deposits around cancer cells in the circulation helps these cells avoid destruction by naturalkiller cells [23]. A comparison of tumor dissemination in control and fibrinogen-deficient mice revealed that the absence of circulating fibrinogen markedly reduced the formation of pulmonary metastases after intravenous injection of cancer cells [24]. Similar results were described in another study of mice tumor model, with fibrinogen-deficiency markedly reducing spontaneous macroscopic metastasis in the lungs and regional lymph nodes. In addition, quantities of pulmonary micrometastases were significantly reduced among fibrinogen-deficient mice after intravenous injection of lung carcinoma cells [25]. Several reports in patients with malignancy have examined the prognostic significance of D-dimer concentrations. Ay et al. prospectively analyzed 1178 cancer patients without VTE over a period of 2 years until VTE or death. Study participants comprised 829 patients (70.4\%) with solid tumors, 148 (12.6\%) with brain tumors and 201 (17\%) with hematological malignancies [26]. Patients were divided into quartiles according to D-dimer concentrations, 
revealing that high concentrations of D-dimer were associated with significantly poorer survival among patients with any type of malignancy. Other reports have examined the prognostic relevance of D-dimer among patients with primary lung cancer. Taguchi et al. measured D-dimer concentrations in 70 patients with lung carcinoma, finding that low levels of $\mathrm{D}$-dimer were predictive of longer survival [27]. Buccheri et al. demonstrated a correlation between prognosis and D-dimer concentration. For 826 patients with lung carcinoma, median survival times were 154 days for patients with above-normal concentrations of D-dimer, and 308 days for patients with normal concentrations [28].

Altiay et al. investigated the relationship between Ddimer level and prognosis in a study of 78 patients with non-surgically treated primary lung cancer [29]. Zhang et al. investigated 232 patients with resected NSCLC, including 17 patients who developed VTE postoperatively, and confirmed the prognostic relevance of D-dimer concentrations [30]. Although the aim and results of that study showed some overlap with our own, our multivariate survival analysis also adjusted for additional factors strongly associated with prognosis, including CEA, smoking, and SUVmax of the tumor. Moreover, our study population was considered more homogeneous, given the lack of postoperative VTE events.

Uni- and multivariate analyses in this study revealed that increased D-dimer levels were predictive of worsened outcomes. Our findings support previous experimental and clinical findings of enhanced tumor progression and unfavorable outcomes in patients showing up-regulated coagulation and fibrinolytic activities. Such results strongly suggest that interactions between angiogenesis and hemostasis facilitate metastasis in patients with NSCLC. In general, the development of postoperative recurrence is likely due to the establishment of micrometastases or the presence of circulating tumor cells (CTCs) prior to treatment. Such cells appear undetectable with current diagnostic modalities, such as $\mathrm{CT}$ and FDG-PET/CT [31]. Given our findings, we speculate that high preoperative levels of D-dimer may be indicative of micrometastasis or CTCs, and thus in turn postoperative recurrence of NSCLC. D-dimer concentrations could therefore offer a predictor of NSCLC recurrence, even though D-dimer is not released by the tumor itself, unlike CEA.

Some limitations must be considered when interpreting the results of this retrospective analysis. The retrospective evaluation of $\mathrm{D}$-dimer levels represents one clear problem. In addition, the study cohort was small, despite being relatively large compared to other such investigations of NSCLC patients.

Given our results and the data from previous basic studies, increased coagulation and fibrinolytic activities appear to be associated with increased risks of tumor progression and metastasis among patients with NSCLC. Concentrations of D-dimer before surgery may also offer a useful marker of recurrence and metastasis in NSCLC patients following radical resection. Furthermore, functional inhibition of fibrinogen and other coagulation factors might represent novel strategies for treating NSCLC. Further investigations are needed to clarify the relationships among circulating coagulation and angiogenic factors in neoplastic tissues.

\section{Conclusions}

The findings of this study suggest that preoperative Ddimer concentration offers an independent predictor of prognosis for completely resected clinical stage I NSCLC, along with age, SUVmax of the primary tumor, and pathological stage. The clinical implications of this finding remain to be determined.

\section{Abbreviations \\ CEA: carcinoembryonic antigen; Cl: confidence interval; CT: computed tomography; CTCs: circulating tumor cells; D-dimer: plasma D-dimer; DIC: disseminated intravascular coagulation; FDG-PET/CT: integrated 18F- fluorodeoxyglucose positron emission tomography/computed tomography; HR: hazard ratio; NSCLC: non-small cell lung cancer; OS: overall survival; RFS: recurrence-free survival; SUVmax: maximum standardized uptake value; VTE: venous thromboembolism}

\section{Acknowledgements}

We acknowledge the assistance of Mr. Tomoyuki Kanno, Yuai Clinic, in the acquisition of study data.

\section{Funding}

No funding body provided support for the design of the study, the collection, analysis, or interpretation of data, or the writing of the manuscript.

\section{Availability of data and materials}

The datasets during and/or that were analyzed during the present study are available from the corresponding author upon reasonable request.

\section{Authors' contributions}

KK wrote the manuscript. KK and KA performed surgery. AK carried out pathological examinations. All authors approved the final manuscript.

\section{Ethics approval and consent to participate}

Ethics approval for this study was obtained from the institutional review board of the Department of Thoracic Surgery, Sagamihara Kyodo Hospital.

This information is included in the Methods section.

\section{Consent for publication}

Not applicable.

\section{Competing interests}

The authors declare that they have no competing interests.

\section{Publisher's Note}

Springer Nature remains neutral with regard to jurisdictional claims in published maps and institutional affiliations.

\section{Author details}

'Department of Thoracic Surgery, Sagamihara Kyodo Hospital, 2-8-18 Hashimoto, Midori-ku, Sagamihara, Kanagawa 252-5188, Japan. ${ }^{2}$ Department of Pathology, Sagamihara Kyodo Hospital, 2-8-18 Hashimoto, Midori-ku, Sagamihara, Kanagawa 252-5188, Japan. ${ }^{3} Y$ Yuai Clinic, 1-6-2 Kitashinyokohama, Kohoku-Ku, Yokohama, Kanagawa 223-0059, Japan. 
Received: 11 September 2017 Accepted: 21 November 2017 Published online: 28 November 2017

\section{References}

1. Sack GH, Levin J, Bell WR. Trousseau's syndrome and other manifestations of chronic disseminated coagulopathy in patients with neoplasms: clinical, pathophysiologic, and therapeutic features. Medicine. 1977;56:1-37.

2. Varki A. Trousseau's syndrome: multiple definitions and multiple mechanisms. Blood. 2007;110:1723-9.

3. Pabinger I, Ay C. Biomarkers and venous thromboembolism. Arterioscler Thromb Vasc Biol. 2009;29:332-6.

4. Pantel K, Alix-Panabieres C, Riethdorf S. Cancer micrometastases. Nat Rev Clin Oncol. 2009:6:339-51.

5. Rut W, Mueller BM. Thrombin generation and the pathogenesis of cancer. Semin Thromb Hemost. 2006:32(Supp1 1):61-8.

6. Batschauer APB, Figueiredo CP, Bueno EC, Ribeiro MA, Dusse LM, Fernandes $A P$, et al. D-dimer as a possible prognostic marker of operable hormone receptor-negative breast cancer. Ann Oncol. 2010;21:1267-72.

7. Blackwell K, Hurwitz H, Lieberman G, Novotny W, Snyder S, Dewhirst M, et al. Circulating D-dimer levels are better predictors of overall survival and disease progression than carcinoembryonic antigen levels in patients with metastasis colorectal carcinoma. Cancer. 2004:101:77-82.

8. Diao D, Zhu K, Wang Z, Cheng Y, Li K, Pei L, et al. Prognostic value of the D-dimer test in esophageal cancer during the perioperative period. J Surg Oncol. 2013;108:34-41.

9. Antonion D, Pavlakou G, Stathopoulos GP, Karydis I, Chondrou E, Papageorgiou C, et al. Predictive value of D-dimer plasma levels in response and progressive disease in patients with lung cancer. Lung Cancer. 2006:53:205-10

10. Sheng L, Luo M, Sun X, Lin N, Mao W, Serum SD. Fibrinogen is an independent prognostic factor in operable non-small cell lung cancer. Int J Cancer. 2013;133:2720-5

11. Zhao J, Zhao M, Jin B, Yu P, Hu X, Teng Y, et al. Tumor response and survival in patients with advanced non-small-cell lung cancer: the predictive value of chemotherapy-induced changes in fibrinogen. BMC Cancer. 2012;12:330

12. Goldstraw P, Crowley J, Chansky K. International Association for the Study of Lung Cancer International Staging Committee, Participating Institutions, et al. The IASLC Lung Cancer Staging Project: Proposals for the revision of the TNM stage groupings in the forthcoming (seventh) edition of the TNM classification of malignant tumours. J Thorac Oncol. 2007:2:706-14.

13. World Health Organization. Histological typing of lung and pleural tumours, 4th edn. 2004; IARC Press, Lyon.

14. Matsumoto K, Kitamura K, Mizuta T, Tanaka K, Yamamoto S, Sakamoto S, et al. Performance characteristics of a new 3-dimensional continuous-emission and spiral-transmission high-sensitivity and high-resolution PET camera evaluated with the NEMA NU 2-2001 standard. J Nucl Med. 2006;47:83-90.

15. Kitamura K, Ishikawa A, Mizuta T, Yamaya T, Yoshida E, Murayama H. 3D continuous emission and spiral transmission scanning for high- throughput whole-body PET. Nuclear Science Symposium Conference Record, 2004; IEEE 2004, Rome, Italy; Vol 5: 2801-2805

16. The Association of Electrical Equipment and Medical Imaging Manufacturers. Performance Measurements of Positron Emission Tomographs. NEMA Standards .Publication NU 2-2001. NEMA, Rosslyn, VA 2001.

17. Matsuguma $H$, Nakahara R, Igarashi S, Ishikawa $Y$, Suzuki H, Miyazawa N, et al. Pathologic stage I non-small cell lung cancer with high levels of preoperative serum carcinoembryonic antigen: clinicopathologic characteristics and prognosis. J Thorac Cardiovasc Surg. 2008;135:44-9.

18. Lim E, Clough R, Goldstraw P, Edmonds L, Aokage K, Yoshida J, et al. Impact of positive pleural lavage cytology on survival in patients having lung resection for non-small-cell lung cancer: an international individual patient data meta-analysis. J Thorac Cardiovasc Surg. 2010;139:1441-6.

19. Shiono S, Abiko M, Sato T. Positron emission tomography/computed tomography and lymphovascular invasion predict recurrence in stage I lung cancers. J Thorac Oncol. 2011;6:43-7.

20. Wojtukiewicz MZ, Sierko E, Klemont P, Rak J. The hemostatic system and angiogenesis in malignancy. Neoplasia. 2001;3:371-84.

21. Chiarug $V$, Ruggiero M, Magnelli L. Angiogenesis and the unique nature of tumor matrix. Mol Biothechnol. 2002;21:85-90.
22. Im JH, Fu W, Wang H, Bhatia SK, Hammer DA, Kowalska MA, et al. Coagulation facilitates tumor cell spreading in the pulmonary vasculature during early metastatic colony formation. Cancer Res. 2004;64:8613-9.

23. Palumbo JS, Talmage KE, Massari JV, La Jeunesse CM, Flick MJ, Kombrinck KW, et al. Platelets and fibrin (ogen) increase metastatic potential by impeding natured killer cell-mediated elimination of tumor cells. Blood. 2005;105:178-85.

24. Palumbo JS, Kombrinck KW, Drew AF, Grimes TS, Kiser JH, Degen JL, et al. Fibrinogen is an important determinant of the metastatic potential of circulation tumor cells. Blood. 2000;96:3302-9.

25. Palumbo JS, Potter JM, Kaplan LS, Talmage K, Jackson DG, Degen JL. Spontaneous hematogenous and lymphatic metastasis, but not primary tumor growth or angiogenesis, is diminish in fibrinogen-deficient mice. Cancer Res. 2002;62:6966-72.

26. Ay C, Dunkler D, Pirker R, Thaler J, Quehenberger $\mathrm{P}$, Wagner $\mathrm{O}$, et al. High D-dimer levels are associated with poor prognosis in cancer patients. Haematologica. 2012;97:1158-64.

27. Taguchi O, Gabazza EC, Yasui H, Kobayashi T, Yoshida M, Kobayashi H. Prognostic significance of plasma D-dimer levels in patients with lung cancer. Thorax. 1997:52:563-5.

28. Buccheri G, Torchio P, Ferrigno D. Plasma levels of D-dimer in lung carcinoma: clinical and prognostic significance. Cancer. 2003;97:3044-52.

29. Altiay G, Ciftci A, Demir M, Kocak Z, Sut N, Tabakoglu E, et al. High plasma D-dimer levels is associated with decreased survival in patients with lung cancer. Clin Oncol. 2007;19:494-8.

30. Zhang PP, Sun JW, Wang XY, Liu XM, Li K. Preoperative plasma D-dimer levels predict survival in patients with operable non-small cell lung cancer independently of venous thromboembolism. Eur J Surg Oncol. 2013;39:951-6.

31. Tanaka F, Yoneda K, Kondo N, Hashimoto M, Takuwa T, Matsumoto S, et al. Circulating tumor cell as a diagnostic marker in primary lung cancer. Clin Cancer Res. 2009:15:6980-6.

\section{Submit your next manuscript to BioMed Central and we will help you at every step:}

- We accept pre-submission inquiries

- Our selector tool helps you to find the most relevant journal

- We provide round the clock customer support

- Convenient online submission

- Thorough peer review

- Inclusion in PubMed and all major indexing services

- Maximum visibility for your research

Submit your manuscript at www.biomedcentral.com/submit
Biomed Central 